http://dx.doi.org/10.12795/PH.1989.v04.i02.19

\title{
VER OTROS MUNDOS: DE MARCO POLO A BENZONI
}

\author{
Manuel Carrera Díaz
}

Quienes se interesan por la literatura de viajes tienen frecuente ocasión de comprobar cuánto cambia el mundo descrito en función de los intereses y características personales del viajero narrador: como resulta fácilmente explicable, una misma realidad, incluso física y tangible, puede adquirir tonalidades completamente diversas según el talante y la óptica del observador. Si ello resulta inmediatamente demostrable contrastando dos relatos contemporáneos de distintos autores sobre una misma parcela de realidad observada, la diferencia de resultados producida por talantes antagónicos se evidencia incluso cuando el tiempo y el espacio de las narraciones son claramente divergentes, como nos ha parecido constatar tras el análisis de las obras de los dos autores de quienes nos disponemos a tratar en estas páginas, y que tienen entre sí grandes semejanzas y no menores diferencias. Por una parte los dos son italianos, los dos viajeros y los dos realizaron, cada uno en su momento, grandes periplos, tanto, que han quedado consignados en la historia, incluida, al menos en el primero de ellos, la literatura. Por otra parte, y refiriéndonos a las diferencias, hay que decir que ambos viajaron en momentos muy distintos - uno en el siglo XIII y otro en el XVI-, a continentes diversos - el primero a Asia y el segundo a América-, y lo hicieron con talante muy diferente, dejando para el recuerdo obras muy distintas. A estas, y a sus concretas características, es a lo que nos disponemos a referirnos a continuación.

Pero antes es necesario conocer, aunque sea sumariamente, a los dos personajes. Poco diremos del primero, pues es sobradamente conocido desde el momento en que no hay historia literaria que omita tratar, aunque sea sucintamente, sobre él, y que ha sido incluso popular a través de otros medios distintos de los escritos. Nos referimos a Marco Polo, el gran viajero veneciano que en $1271 \mathrm{em}-$ prendió el gran periplo hacia la corte de Kublai Kan, donde permaneció hasta 1292, con llegada definitiva a Venecia tres años más tarde, y que poco después, 
en las cárceles de Génova, dictó a su compañero Rustichello la memorable relación contenida en su archifamoso Millón.

$\mathrm{Al}$ segundo de estos personajes debemos hacer una referencia más detallada, puesto que su biografía, su obra e incluso su existencia no son de dominio tan general. Nos referimos al milanés Girolamo Benzoni, del que en realidad, y por mucho que se exprima la documentación de su tiempo, no se puede decir, biográficamente hablando, gran cosa. Se le conoce por haber legado a la posteridad un librillo con el ampuloso título de Historia del Nuevo Mundo ${ }^{1}$, en el que relata su viaje a América y su estancia en este continente entre 1541 y 1555 . Se trata de una obrita que tuvo gran difusión incluso - o mejor dicho, sobre todo- fuera de Italia, ya desde su publicación en 1565 y hasta el siglo XVIII e incluso XIX, siendo objeto de más de una treintena de traducciones y ediciones al latín y a las principales lenguas europeas (alemán, francés, neerlandés e inglés), excluida la española, a la que no se vertió hasta 1967, por tratarse de una visión demasiado agria y acibarada de la obra de España en América; traducción esta, por otra parte, realizada y publicada en Venezuela, que ha sido seguida por otra publicada ya en España. Los escasos datos que se poseen sobre Benzoni han sido recabados de esa obra, que es a su vez la única que se le atribuye, y que no resulta, por otra parte, demasiado explícita en esta cuestión. El autor afirma en ella que es milanés, y que cuando inició su viaje a América, en 1541, tenía veintidós años, de donde se deduce que había nacido en 1519. Se ignora la fecha de su muerte; algunos la sitúan después de 1572, año en que se publicó en Italia la segunda edición de su obra, suponiendo que ello debió de ocurrir en vida del autor; otros, por el contrario, argumentan que precisamente la presencia de ciertas vistosas erratas existentes en él constituyen demostración suficiente de que no pudo cuidar y seguir de cerca la reedición por haber fallecido con anterioridad a la misma.

Las breves reconstrucciones biográficas intentadas hasta el momento se basan en meras suposiciones operadas sobre una base documental prácticamente inexistente, o bien en conjeturas elaboradas a partir de los escasos datos que sobre sí mismo ofrece en su obra. Por la identidad de apellidos, sostienen algunos que perteneció a la noble familia milanesa de los Benzoni, pero no se ha hallado ningún documento que pruebe que tal identidad nominal haya implicado asimismo parentesco. Como más probable ven otros autores que perteneciese a otra familia del mismo nombre y lugar, aunque de menos rancio abolengo, dedicada al artesanado o al comercio. Su nombre no figura en los Catálogos de pasajeros a Indias hasta ahora publicados. Se ha citado un solo documento, mencionado por el polígrafo chileno José Toribio Medina, en el que se haga referencia a él; se trata de una cédula en la que se le define como «platero natural de Milán y vecino de Honduras», y señala que en 1555 fue reconciliado como hereje luterano por el Arzobispo de Méjico en su carácter de inquisidor ordinario. Pero nada de esto aparece reflejado en el relato de Benzoni, quien de esa fecha se limita a señalar

1 La Historia del Mondo Nuovo di M. Girolamo Benzoni Milanese. La qual tratta dell'isole, \& mari nuovamente ritrovati, \& delle nuove città da lui proprio vedute, per acqua \& terra in quattordeci anni. In Venetia, appresso Francesco Rampazetto, ad instantia di Gabriel Benzoni, 1565. 
que fue aquella en la que tomó la decisión de regresar a su tierra natal. Con tan escasos datos y evidencias documentales, y dado el sesgo, al que luego nos referiremos, claramente predeterminado de su relato, no es de extrañar que ya tempranamente surgieran dudas sobre la veracidad del carácter testimonial del relato, e incluso sobre la propia existencia del autor.

Estos son nuestros dos personajes. No vamos a entrar ahora aquí en los juicios polémicos que se han dado sobre cada uno de ellos: es decir, si Marco Polo fue tan fantasioso como sostenían sus contemporáneos, hasta el punto de propinarle el apelativo el apelativo, que luego se extendió a su obra, de Millón, por «estar siempre hablando de la grandeza de los dominios del Kublai Kan, de los millones de renta, de los millones de juncos, de los millones de jinetes» ${ }^{2}$. Consideraciones de este tipo ya indignaron en su tiempo a «messer Marco», como lo denomina Ramusio, e incluso lo persiguieron hasta en su lecho de muerte, si es cierto lo que refiere el dominico Jacopo de Acqui, quien cuenta que «le fue pedido por sus amigos, en su lecho de muerte, que corrigiera el libro eliminando todo lo que fuese más allá de los hechos, a lo cual su respuesta fue que no había contado ni la mitad de lo que en realidad había visto ${ }^{3}$. Y, como personaje famoso que fue, incluso más allá de su muerte: precisamente unos de los protagonistas del relato de Benzoni, el bachiller Martín Fernández de Enciso, que tuvo una controvertida actuación en la desafortunada expedición de Alonso de Ojeda a la actual región colombiana del golfo de Urabá, se permitió escribir, en su no muy brillante Suma de geograhiía (1519), y en malévola referencia a Marco Polo, que «Desd'el Ganges a la parte del Oriente, que es la postrera India, a que llaman Catayo e a do fueron las tierras del Preste Juan e la de Got y Magot no ay escriptura auténtica más que la del rey Sodiano, porque, si algunos mercaderes han passado allá, han visto poco y aquello escríbenlo dudoso e poco sin orden, e assí en todo de poca fe» ${ }^{4}$.

Ni vamos a entrar tampoco, por el otro lado, a considerar si el libro de Benzoni, como quiso André Thévet, fue un puro montaje escritoy urdido por los enemigos de España para producir su descrédito ante la opinión europea, es decir, si su autor es un pseudo viajero que tal vez nunca existió y cuya relación fue pura y llanamente inventada por los calvinistas ginebrinos y holandeses con la intención de poner su granito de arena para que se desviasen hacia sus bolsillos los tesoros que seguían entrando Guadalquivir arriba.

Lo que pretendemos, simplemente, es poner sobre el mismo atril los dos libros y ver cómo cada uno de los dos autores ha abierto los ojos ante el asombroso mundo que se les presentaba. Es cierto que se trata del producto de autores de muy distintas épocas, y que se refieren a dos territorios no comparables, pero no lo es menos que ambos, en el momento de partir, se enfrentaban a posiciones

2 Eileen Power, Gente medieval. Barcelona, Ariel, 1987, p. 105.

3 En su Imago Mundi. Citamos por Power, op, cit, p. 109.

4 Citamos por Juan Gil, «Libros, descubridores y sabios en la Sevilla del quinientos», introducción a El libro de Marco Polo anotado por Cristóbal Colón. El libro de Marco Polo de Rodrigo de Santaella, Madrid, Alianza Editorial, 1987, pp. xlviii-xlix. 
vitales semejantes ante la inmensidad de lo semidesconocido, a experiencias tan distintas a las que estaban acostumbrados, y tan dilatadas en el tiempo como para merecer ponerlas por escrito.

Lo primero que nos llama la atención es la distinta forma del relato. El $\mathrm{Li}$ bro de Marco Polo es una pormenorizada relación casi cartográfica de los territorios asiáticos visitados, y de hecho constituyó una fuente en la que bebieron no pocos cosmógrafos posteriores, en cuyos mapas se lee a menudo la referencia explícita al propio nombre de Marco Polo, hasta el punto de que se le ha considerado una «víctima de la cartografía» ${ }^{5}$, deplorando su «triste sino de acabar trasvasado a las cartas geográficas» ${ }^{6}$. Pero es que el veneciano da pie para ello, porque, aparte de haber sido durante mucho tiempo la única fuente fiable sobre la constitución de aquellos parajes orientales, da la impresión de que, mientras le dictaba a Rustichello, iba recorriendo mentalmente un pormenorizado mapa que llevaba en el recuerdo o en sus apuntes. No de otra manera se explican los colofones de cada capítulo, que son de este tenor: «Or lasciamo queste parti e andiamo verso tramontana» ${ }^{\text {; }}$ " Or lasciamo questo reame, e conteremo di una diversa gente ch'è lungi da questa provincia dieci giornate» 8 ; «Or ci partiamo di qui e andiamo inanzi; perció che ci converrebbe entrare in India, e noi non vogliamo entrare; perché a ritornare della nostra via conteremo tutte le cose d'India, per oodine. E perciò ritorneremo a nostre provincie verso Baudascia ovvero Balauscian, percioché d'altra parte non potremo passare ${ }^{9}$, frases estas últimas que son todo un programa de relación cartográfico-textual. Hasta tal punto pretende Polo cumplir su ordenado programa expositivo, que hace incluso referencia a aquellas regiones de las que no tiene casi nada que decir, como es el caso de la provincia de Carcam (Yarkand), de la que señala: «Carcam é una provincia che dura sei giornate; e adorano Malcometto, e sonvi cristiani nestorini; e hanno grande abondanza d'ogni cosa. Quivi non v'ha altro da ricordare. Or lasciamo qui, e diremo di Cotam» ${ }^{10}$. Polo da constantes mediciones de la extensión del territorio medidas en jornadas de camino, («Cotam... dura otto giornate») y ofrece muy a menudo la orientación («Cotam è una provincia tra levante e greco»). El lector, pues, tiene la impresión de ser llevado en perpetuo movimiento sobre un mapa, movimiento que se detiene temporalmente cuando se narra una anécdota referida a las gentes de los lugares por los que pasa, o incluso una leyenda con todas las características del relato mágico, como es el caso de la del Viejo de la Montaña.

Por su parte, el libro de Benzoni se presenta como un relato de viajes sobre el que se insertan los fragmentos de crónica que deben configurar esa historia que da título al libro. Hay, pues, dos planos claramente diferenciados: uno, el viaje, que funciona como marco; otro, la crónica histórica, que constituye el contenido

5 Juan Gil, op. cit., p. Ixvi.

6 Ibídem, p. Ixiii.

7 Il libro di Marco Polo detto Milione, ed. de Daniele Ponchiroli, Torino, Einaudi, 1982, p. 30.

8 Ibidem, p. 38.

9 Ibídem, p. 39.

10 Ibidem, p. 42. 
esencial y claramente privilegiado de la obra. En el fondo, el procedimiento recuerda al puesto en práctica en tantas ocasiones, en el sector estrictamente literario, por los autores de libros de cuentos o relatos cortos que, para garantizar la unidad formal del conjunto y disponer al mismo tiempo de una plataforma ideológica, adoptan el uso de un marco contenedor de las distintas unidades narrativas. A estas dos razones justificativas, que valen también para la obra de Benzoni, se añade aquí una tercera, dada la índole del relato: el marco funciona al mismo tiempo como elemento autentificador, como signo de veracidad y testimonio. En el marco se describe el viaje del autor desde Milán hasta América, su estancia en la zona del Caribe y el Perú durante casi quince años y su posterior regreso a Italia.

Ahí, en la ausencia o presencia de ese marco es donde radica la primera importante diferencia entre los dos relatos viajeros. En el Libro de Marco Polo, y guiándose el autor por su deseo de objetividad, faltan prácticamente las referencias personales, el marco autobiográfico que hoy nos parece indispensable, «se non altro per l'opportunità di disporre le prospettive secondo un punto di vista centrale» ${ }^{11}$; hay en él a este respecto, en realidad, sólo una mínima e inevitable introducción, y alguna que otra perdida referencia. Hoy se nos antoja que ese tono impersonal no sirve, en realidad, más que para privarnos de una parte sustancial de la información que de un relato narrado más de cerca y «en caliente» hubiera podido extraerse. No sabemos, por ejemplo, cómo vivió Marco Polo en China, qué aventuras cotidianas y personales hubo de afrontar, cuáles eran sus reacciones personales frente a aspectos tan elementales como la comida indígena, etc. Falta, pues, ese nivel que podría considerarse anecdótico y que es sin embargo una fuente inagotable de datos caracterizadores de un estilo de vida, de un ambiente y, en definitiva, de una historia. A pesar de su riqueza y de su fantasía, la lectura del Libro de Marco Polo frustra, como acertadamente indica E. Power ${ }^{12}$, algunas de las expectativas del lector actual: lo hace en el aspecto indicado, y lo hace también al omitir cualquier referencia a diversas costumbres características de los chinos, tales como vendar los pies de las mujeres y pescar con cuervos marinos (usos que sí serán descritos más tarde por Oderico de Pordenone); es curioso, asimismo, que no mencione nunca la costumbre de beber té, y que no diga ni una sola palabra sobre la Gran Muralla.

Benzoni, por el contrario, aparece presente en el relato, y precisamente en ese marco -o «cornice», según el difundido término italiano- de que he hablado. Lo que ocurre es que lo hace de una manera tan caótica y desordenada, que resulta incluso difícil reconstruir el esquema general de su viaje, y sobre todo la cronología del mismo, que es imprecisa y errática: es capaz, por ejemplo, de recordar que pasó cuarenta y cuatro días en Cartagena de Indias esperando la llegada de una nao, pero no se preocupa de especificar si llegó a América en 1541 o 1542 , por no hablar de la datación de los viajes menores. Nos cuenta que vivió casi quince años en América, pero es muy poco explícito sobre lo que hizo allí

11 Sergio Solmi, «Introduzione» a Il Libro di Marco Polo detto Milione, op. cit., p. VIII.

12 Op. cit. 
en esos tres lustros. Aparte de las dos ocasiones en que se nos presenta como soldado expedicionario en cortas incursiones de conquista, nada más sabemos al respecto. Sus andanzas por Panamá, Ecuador, Guatemala, Nicaragua y Santo Domingo parecen presentadas, por la falta de referencias personales, más como el apresurado relato de un turista que como la crónica de alguien que, de haber recorrido realmente ese itinerario, hubo de sufrir en su persona más de un avatar digno de ser relatado. Nada menos que cuatro años de estancia en Nicaragua se despachan con la simple indicación de que allí sufrió «una larga y grave enfermedad», hecho ante el cual el lector no puede dejar de preguntarse, entre otras cosas, qué enfermedad pudo ser aquella, si duró los cuatro años completos, y cómo, dónde y de qué vivió el protagonista durante tan largo período. En otras palabras, si Benzoni dice algo de sí mismo, oculta mucho más. Pero, eso sí, su voz está presente en el relato para censurar las costumbres de los indios o lanzar pullas que pretenden ser sarcásticas y terminan siendo ingenuas contra los españoles culpables de tantos males en América.

En definitiva, nuestra curiosidad no queda satisfecha en el caso de Marco Polo porque éste se autoelimina del relato, y no lo queda en el caso de Benzoni porque éste aparece en él sólo como quiere y cuando quiere. ¿Hay alguna explicación para estas dos diferentes actitudes que, curiosamente, terminan llevando a parecido resultado? La hay, a mi entender. Marco Polo se esconde porque, en una actitud muy medieval, quiere apartar de su relato lo subjetivo e individual: su autoanulación responde, pues, a una búsqueda de verosimilitud y objetividad. En el caso de Benzoni, no parece atrevido concluir que su libro no nació de un ansia de desahogo personal, de una tentación biografista o del sutil pero omnipresente espíritu de protagonismo informativo propio de quien ha vivido una gran aventura personal, condición esta última que sí parece evidente en el caso de Marco Polo. Benzoni quiere vengarse de los españoles por haberse visto obligado a regresar pobre a Italia, después de quince años de difícil vagabundeo, y lo hace contando el descubrimiento y conquista de América a su manera, procurando que su presencia en el relato sirva para presentar su contenido como fruto de lo constatado por un testigo presencial.

La mirada de ambos ante lo que se presenta delante de sus ojos es totalmente diferente, porque diferente es la geografía, las condiciones históricas y, sobre todo, las circunstancias personales y su relación con lo narrado. Marco Polo observa con la mirada asombrada y ávida del viajero, y anota con el realismo del comerciante, los datos de un mundo sorprendente por su desmesura, llamativo por su novedad y apetecible por su riqueza. Benzoni, más que hacer un viaje, lo sufre, y desahoga su resentimiento de aventurero fracasado intentando presentarse, pese a su evidente incultura, como el europeo superior a los indígenas y el moralista censor del pésimo comportamiento de los conquistadores. Si Marco Polo se asombra ante la inmensidad de las estepas asiáticas, ante la hormiguente población y la multitud de los ejércitos asiáticos, ante los inmensos ríos y las pagodas de oro de Birmania, si casi siente tintinear en su bolsillo los «venecianos» de oro que podrían obtener con las mercaderías que halla por todas partes, Benzoni no ve en América sino mares tempestuosos, territorios agrestes, espesísimas selvas, sór- 
didos poblados con chozas de caña, irritándose con Cieza de León porque este osa comparar el tráfico marítimo de Panamá con el de Venecia, cuando, según él, todas las ciudades de América fundadas por los españoles, puestas juntas, no llegan ni siquiera a las dimensiones del barrio de Porta Comasina en Milán.

Estas actitudes comportan, evidentemente, diferencias en la narración. La de Marco Polo es casi una descripción hecha a vista de pájaro. La de Benzoni pretende ser más inmediata, con el pie puesto en tierra. La reseña del territorio, es, en ambos casos, muy sumaria. Si Marco Polo parece un auténtico tragamillas, Benzoni no le va a la zaga, teniendo en cuenta sobre todo que su espacio descrito es territorialmente mucho menos extenso; sólo un ejemplo: el territorio de Yucatán se despacha en su relato diciendo, simplemente, que «es muy rocoso». Marco Polo, como indicaba antes, presenta la ventaja añadida de guardar orden en la narración, lo que no es el caso de Benzoni, que además de describir quiere dar una historia de la conquista y aprovecha por tanto cualquier ocasión para introducir datos históricos claramente copiados de cronistas como López de Gómara, Fernández de Oviedo, Pedro Mártir o Cieza de León. De pasada, aquí radica otra notable diferencia: si el relato de Marco Polo se presenta como una crónica directa, el libro de Benzoni es fruto en su mayor parte, de un plagio descarado.

Por lo que respecta a la referencia a las circunstancias climáticas, tan socorridas y siempre presentes en los relatos a tierras extrañas, sorprende la escasa importancia que, en comparación concretamente con Benzoni, les atribuye Marco Polo, quien pocas veces se refiere a ellas, y siempre en circunstancias muy extremas. Creemos que se pueden contar con los dedos de la mano: al hablar de la India dice que «V'ha sì gran caldo ch'é maraviglia; e vanno ignudi; e non vi piove se no tre mesi dell'anno, giugno, luglio e agosto; e, se non fosse questa acqua che rinfresca l'àiere, e' vi sarebbe tanto caldo che niuno vi camperebbe» ${ }^{13}$. Exagera evidentemente cuando al hablar de Quilón, en la costa de Malabar, sostiene que «Qui hae sí grande caldo che a pena vi si puote sofferire, che, se togliesse uno uovo e mettessolo in alcuno fiume, non anderesti quasi niente che sarebbe cotto» ${ }^{14}$, y tiene uno de sus raros destellos de humorismo cuando señala que en «tutta la provincia di Mabar [la costa de Coromandel en la India] non fa loro bisogno sarto, peroché vanno tutti ignudi d'ogni tempo; peroch'egli hanno d'ogni tempo il tempo temperato, cioè né freddo né caldo» ${ }^{15}$. Benzoni tiene en el clima un argumento preferido, refiriéndose a las grandes borrascas caribeñas y atlánticas, a los terroríficos huracanes, a la sorprendente inversión de las estaciones en relación con Europa, a las tempestades de las costas de Ecuador y Perú y a los fríos andinos. Cierto que no hay comparación entre la endeblez de los datos benzonianos y el detalle de las grandes crónicas americanas, pero la diferencia existe con relación a Marco Polo.

13 Il libro di Marco Polo detto Milione, op. cit., p. 180.

14 Ibidem, p. 192.

15 Ibidem, p. 176. 
Diferencias hay también por lo que se refiere a la flora y la fauna. Marco Polo es, en el fondo, un comerciante, y apenas tiene ojos para una mercancía tan perecedera como son las flores, los frutos y las plantas. A él lo que le llama la atención son las mercancías, las joyas, los diamantes o las sedas. En todo caso, a él las plantas le interesan ya metidas en frasco o ensacadas, es decir, convertidas en especias, esa casi incomprensible pasión medieval. Aun señalando en ocasiones que en tal o cual región hay frutos muy diferentes de los europeos, no se toma la molestia de describirlos. Benzoni, ante la exuberante flora centroamericana, no puede hacer otro tanto, aunque sólo sea por no alejarse de la tradición que había inaugurado Fernández de Oviedo, si bien no llega a ofrecer grandes novedades al respecto. La primera planta a que se refiere es a la del tabaco, dando de él una descripción y atribuyéndole unos efectos claramente narcóticos que no se corresponden con las nociones que sobre ella hoy tenemos. Le interesa también el cacao, a propósito del cual, tras constatar su importancia comercial, se ocupa de apagar el posible interés del lector señalando que es más bien «una bebida de cerdos». Aparte de esto, presta atención al maíz y a algunos tipos de frutas en aquel entonces obligadamente exóticas para un europeo (guayabas, aguacates, mameyes, etc.), demostrando claras preferencias por los plátanos y las piñas.

En la descripción de la fauna se deja sentir con claridad la distancia de siglos que media entre ambos autores. Marco Polo enumera las especias de animales que encuentra en su viaje, pero no las describe, y cuando lo hace, parece que se refiere a seres de fábula. Hemos encontrado al respecto sólo cuatro excepciones, es decir, las descripciónes relativamente pormenorizadas de otros tantos animales. En primer lugar, la gran serpiente de Carayam, de la que dice: «E in questa provincia nasce lo gran colubre e'l gran serpente, che sono sí smisurati, ch'ogni uomo se ne dovrebbe maravigliare. Egli sono molto orribile cosa a vedere: e sappiate ch'egli ve n'ha per vero di quelli che sono lunghi dieci gran passi, e sono grossi dieci palmi; e questi sono li maggiori. Egli hanno due cambe dinanzi presso al capo, e gli loro piedi sono d'una unghia fatta come di lione; e il celfo è molto grande, e lo viso è maggiore ch'un gran pane; la bocca èe tale, che bene inghiottirebbe un uomo al tratto; egli hae denti grandissimi, ed è sí smisuratamente grande e fiero, che non è uomo né bestia che nollo dotti e non abbia paura; e ancora ve n'ha di minori d'otto passi o di sei» ${ }^{16}$. El animal es, como puede adivinarse, un cocodrilo. Encontramos luego a los unicornios, los cuales, «nel mezzo della fronte hanno un corno nero e grosso; e dicovi che non fanno male con quel corno, ma co' la lingua, ché l'hanno ispinosa tutta quanta di spine molto grandi. Lo capo hanno come di cinghiaro, la testa porta tuttavia inchinata verso la terra; ed istà molto volentieri tra le buoi [versión correcta: tra la melma e il fango]: ella è molto laida bestia a vedere», descripción esta bajo la que es más fácil adivinar la figura del rinoceronte. Hallamos luego la descripción de unos supuestos hombrecillos «ch'hanno la coda lunga piú d'un palmo (...) e dimorano nelle montagne di lungi dalla città. Le code sono grosse come di cane», y que no son tales, sino simples orangutanes. Y, finalmente, la descripción de la jirafa, que ahorraremos aquí por no alargar esta relación. 
Benzoni es más prolijo en este sector. Desfilan por sus páginas las niguas, las tortugas, las iguanas, los pumas y jaguares, los tapires, los vampiros, los manatíes, los pavos, las llamas del Perú, etc. Se trata de descripciones bastantes sumarias, en poco comparables a las de un Fernández de Oviedo. En Benzoni, de todas maneras, hay ya una visión más moderna y empirista del mundo animal si la comparamos con Marco Polo, que, como hemos podido ver, ofrece todavía descripciones fabulosas y casi mágicas de ciertos animales.

Pero en un territorio no sólo hay un suelo, unas plantas y unos animales, sino, frecuentemente, unos hombres. En la descripción etnológica entran, como era de esperarse, ambos autores. El canon descriptivo de Marco Polo suele centrarse sobre el aspecto físico de los nativos, la religión, el tipo de alimentación, la organización familiar y social y sus recursos materiales. Por cierto que el viajero veneciano, según se desprende de su relato, miraba, antes que a nadie, a las damas, puesto que nunca deja de señalar que las mujeres de tal o cual región son especialmente hermosas, declarándose rendido admirador de las de la región de Damagán, en el nordeste de Persia. Se molesta también en contar, quizás con mal disimulada envidia, el número de mujeres que componen los harenes de los reyes que gobiernan las distintas regiones, y no deja de llamar la atención sobre algunas extrañas costumbres que observa. Se escandaliza, por ejemplo, como le ocurriría a cualquiera, de que en la región de Kien-Chang, cuando llega un forastero a un poblado, los maridos le cedan a sus mujeres e hijas y se ausenten de la casa familiar mientras aquel desea permanecer en ella y con ellas (la cosa, por cierto, también le llamó la atención a don Hernando Colón, quien leyó atentamente el ejemplar del libro de Marco Polo que había pertenecido a su padre y aún conservado en la Biblioteca Colombina, y, al llegar a este pasaje, anotó al margen: «manera admirable de hospedar a los extranjeros» ${ }^{17}$ ). Le llama la atención el que en la región de Yung-Chang exista la costumbre de que, cuando una mujer da a luz un hijo, se levanta inmediatamente para dejar su lugar en el lecho al marido, quien permanecerá en él durante cuarenta días lavando y cuidando al niño y recibiendo las visitas de parientes y amigos, uso que los nativos explicaban diciendo que bastante trabajo había tenido hasta el parto la mujer, y que hora era que desde ese momento le tocara hacer algo al marido. Estos curiosos y sabrosos detalles suelen faltar en Benzoni, quien da muestras de unas tendencias etnológicas mucho más severas y puritanas, ocupándose con más amplitud que el veneciano en describir la vestimenta, la medicina, el armamento y la religión de los indígenas, así como en hacer referencia a ciertos usos que son moneda común entre los cronistas de la época: el uso de hamacas, los efectos del curare, la utilización de piraguas, la elaboración de la chicha, el desprecio de los indios hacia el valor no exclusivamente ornamental de las joyas, etc. En Benzoni, por otra parte, se dedica amplio espacio a comentar el proceso de evangelización de los indios y su actitud ante los conquistadores, temas estos que obviamente no pueden tener paralelo en el libro de Marco Polo. Ambos viajeros coinciden en sus muestras de horror ante el canibalismo que se practicaba tanto en Asia como en América, y, como buenos

17 El libro de Marco Polo anotado por Cristobal Colón, op. cit., p. 47. 
europeos, no dudan en calificar de pusilánimes y cobardes a los pueblos que no demuestran simpatía por la guerra.

En ambos libros hay, además, una parte de historia. En Marco Polo, referencias puntuales a los hechos históricos de algún pueblo, dinastía o rey al que en ese momento se hace referencia, contada siempre con el distanciamiento y la amabilidad de quien ya la ve convertida en leyenda. En Benzoni, que se siente implicado en los hechos históricos que narra, la agria y manipulada versión de la conquista de América por parte de España, en la que no se ve sino sangre, muerte y destrucción. Y es que, como decíamos al principio, Marco Polo hizo un viaje, mientras que Benzoni lo sufrió. No es este el lugar adecuado para sacar moralejas, pero nos parece que es más cómodo, e incluso más ético, lo primero. 